\title{
"Markhi" spatial design structure: numerical study of its work under static load
}

\author{
Vadim Alpatov ${ }^{1, *}$ \\ ${ }^{1}$ Samara State Technical University, Institute of Architecture and Civil Engineering, \\ Molodogvardeyskaya str. 194, 443001 Samara, Russia
}

\begin{abstract}
There is a problem of internal stress volume existing for some types of spatial structures and their joint connections. The problem occurs when a massive body is used as a joint connector. It is quite simple to determine tension on this joint connector surface using electric resistive tensometry method. It is not simple though to empirically determine internal tension in the massive body of the connector. To determine internal tension we can use modern calculation systems, such as Ansys, Abaqus, CosmosWorks, Nastran, Autodesk Inventor, Robot Structural Analysis, Bentley STAAD, CSI SAP2000; etc: Internal tension analysis in a massive joint connector makes possible to select both surplus stock parts and shortage stock parts. In this paper the authors base their analysis on both surface and internal tension of MARKHI connector and come up with solutions for its improvement.
\end{abstract}

\section{Introduction}

Many elements converge in joints of spatial lattice design structures (SLS). The peculiarity of the SLS is that each element here is involved in receiving of external load and transferring this load to the foundations [1-5, 20, 21]. Each item of the SLS also possesses some internal force which it transfers to the joint connection. Joint connection in this case accepts many differently directed loads coming from adjoining elements. Thus, the joint work here can be described as combined stress state [2, 4-11].

\section{Main Part}

Traditionally, experimental methods are used to study stress-strain behaviour (SSB) of joint connections. The most popular method here is the electric resistive tensometry method. Experimental methods make it possible to determine the level of tension only on the surface of the item tested. It is not possible to determine internal stress by experimental methods. In practice the internal stresses in the tested item are determined when judged by stresses on its surface. This method proved valid for thin-walled elements. Internal stress for massive bodies can be calculated that easy. As for massive bodies with complex internal geometry,

*Corresponding author: avu75@mail.ru 
cavities and holes, it is almost impossible to assess their internal stress judging by their surface stresses.

Modern calculation software systems allow to calculate internal stress in almost all the models. While analyzing SSB of commuter models, modern calculation systems make it possible to peep inside these models and to build any cross-section with a distribution level of internal stresses $[6,8,9]$.

When SLS is designed, the method of material concentration in places with high levels of stress and in places requiring increased reliability is widely used. SLS joins are often quite massive as they are made of steel with high or increased strength So, this is the way how the reliability of responsible joints is increased in practical conditions. It also helps to prevent "uncertainty" of internal stresses.

The most well-known joints if spatial structures (Mepo, Orona, Cubotto, Veymar, Markhi, Kislovodsk) have either a solid ball or a holed polygon as their basis. Up to 16 cored can be jointed together in such systems. R.I. Khisaimov showed in his research that joints weight ratio can reach up to $40 \%$ of the whole SLS weight [11]. In terms of the theory of structures optimal design, joint elements are referred to auxiliary elements, unlike rods which are referred to the essential elements $[12,13]$. One of the commonly accepted ways to optimize designs is to reduce the size and number of support elements. Chamferless trusses made of bend-welded profiles can serve as an example of successful implementation of this principle. In these trusses the principle of refraining from joint connectors (supporting elements) is implemented to the fullest extent. As a result, the weight of such trusses is considerably smaller than the weight of gusset plates. Thus, reducing the weight of joint connectors can help reduce steel spread up to $40 \%$.

The authors are sure that it is possible to reduce materials consumption of SLS while studying the reserves of joint connectors load bearing capacity by computer modeling. SLS with joints made on the basis of filled-in massive details of MARKHI type. The aim of this research is to study the distribution of internal stress in MARCHI joint connection and to find ways to reduce its materials consumption. To achieve this goal the authors used a heel joint of MARKHI spatial structure as the object of study.

The authors took all necessary input data for their study from a famous project. A heel joint was selected for analysis because of the following reasons. Firstly, this joint is the most loaded in the structure, secondly, the way this joint is fixed to the column is the most typical for describing clearly the boundary conditions of fixing, thirdly, demands of maximum reliability are usually applied to support members due to the possible maximum damage in the development of progressive destruction $[14,15]$.

Modeling of the joint geometry was done in SolidWorks software system. While creating the model of this joint connector, the authors did their best to take into account the most essential features of its design, such as: internal and external geometry of the joint connector, adjacent coupling (nuts) and bolts, the difference of physical and mechanical characteristics of the materials (due to the use of different steels). Some of the features of the joint connections had to be disregarded because of the complexity of the model. Their influence on the final result was considered as non-essential. Thus, the research simplified: screwed connection as well as conditions under which the connector bears against the column. Screwed connection was substituted with a solid contact on surfaces of the bolt and the connector.

The way the connector is supported is in practice a relatively "free" notion, implemented through the centralizer and safety angle stops installation. Vertical forces from the connector to the column are transmitted along the lower side of the connector. Horizontal loads are perceived by the friction forces, and for an emergency case safety angle stops are applied. The model under analysis excludes the column and its structural elements (that is centralizer, angle stops, etc). The way the joint is supported was modelled 
by means of rigid fixing of the lower side of the connector. It corresponds to a situation in which the force of friction on the surface of the lower side of the connector holds all possible horizontal efforts, i.e. the situation of regular operating mode.

As a result of calculation of the joint connection model the authors determined tension both on the surface of the connector, and inside it. This computational model makes it possible to display stress fields of cross section. Figure 1 shows internal tension in a joint connector.

As expected, tension at the connector surface does not exceed proof stress for the material. It means that externally connector is in the elastic stage. Exceptions here are the areas under adjoining nuts. In an assembled joint these areas are hidden and they have to therefore be attributed to inside areas of the assembled unit.

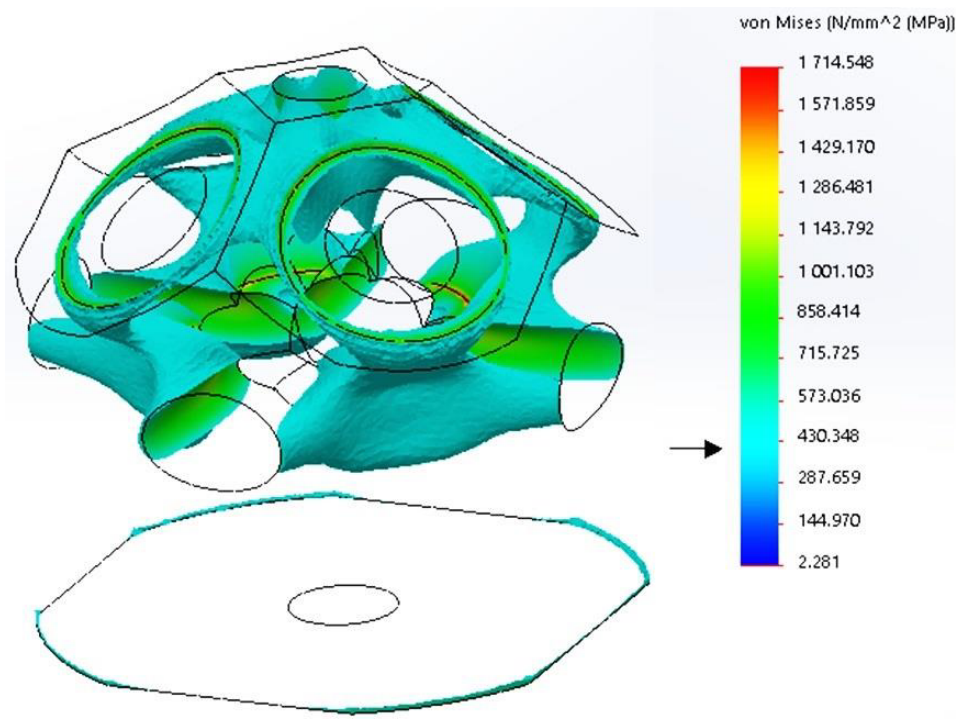

Fig. 1. Internal tension in a joint connector.

Inside the connector the researchers found come small areas with tension exceeding that of nominal yield strength steel as well as smaller areas with tension exceeding greater than the tensile strength of steel (fig. 1). The latter should be referred to the so-called "emissions", characteristic for the calculation models done by software systems and working on the basis of the finite element method. These areas are affected by a wellknown fact stating that there are usually sections with peak values of calculation results in the areas of joint (dot) load application and in the areas of joints fixing (boundary conditions). Peak values should be neglected when determining the scope of reliable solutions empirically. Areas with peak tension values occur along the edge of the supporting surface of the connector, on the edge of the nut and on the bolt and connector contact surfaces. If we exclude these areas form the analysis, we can conclude that the whole volume of the connector massive body is within the scope of tension which is within the strength limit. Inside the volume there are small areas with the scope of tension greater than nominal yield stress of steel (that is in case the worst possible combination of loads is taken into account).

For the connector geometry under analysis the distribution of the material by its volume turned out to be rational. It proved impossible to reduce its mass by simply reducing of its size.

Internal stress distribution in a massive body with inside holes (made as cross-holes for bolts) is characteristic for crystallographic structures. Tensions in such a massive body are 
concentrated in accordance with stress application and are distributed onto the supporting structure through shortcuts. Porosity in the upper part of the massive body (bolt installation place) causes concentration of tension in "narrow" parts. The level of tension declines in the lower side of the connector massive body (closer to the supporting surface). There's more material and less porosity in this part of the body. Surface areas of the connector (which are comparatively far from the borders of contacts connector-nut and bolt connector) are involved in the work of the joint comparatively seldom. To these areas we refer outer edges of the faces of the polyhedron connector. In these areas the material can be removed completely, with the result that the from of the connector will become a ball characteristic for a Mero joint (out of a polyhedron) (see Figure 1).

It is also possible to reduce the consumption of steel used for a massive joint connector by changing its design and form. For example, the joint can be formed as a hollow spherical shell of high-strength steels. In this case, there will be no internal stresses typical for massive connectors [16-18]. Power lines here will be distributed along the surface of the shell causing surface tension only. They can be easily verified by using electric resistive tensometry method. SDC, Nodus, NS, Oktaplatta, Vestrut and other systems are examples of such joints.

\section{Conclusion}

The research yielded the following conclusions:

1. Tensions at the connector surface coming from calculated loads do not exceed that of nominal yield strength steel.

2. The maximum tension at the connector surface occurs on the supporting surface and in the parts where nuts and connector contact, i.e. under the nuts.

3. There are some small areas with tension exceeding that of nominal yield strength steel.

4. Areas with high internal stresses are located in the bolt and connector contact surfaces.(screw connection area) and inside of the connector in the areas serving as crossholes for bolts.

5. For the connector geometry under analysis the distribution of the material by its volume turned out to be rational. It proved impossible to reduce its mass by simply reducing of its size.

6. It is possible to reduce the consumption of steel used for a massive joint connector by changing its design and form. For example, the joint can be formed as a hollow shell.

\section{References}

1. I.S. Kholopov, M.I. Balzannikov, V.Yu. Alpatov, Vestnik VolgGASU 28, 225-232 (2012)

2. V.N. Trofimov, G.B. Begun, Structural Constructions (Stroiizdat, Moscow, 1972)

3. I.S. Kholopov, V.Yu. Alpatov, V.N. Mochalnikov, N.N. Moiseev, V.Yu. Vetschin, Modernization and development of metal, timber and plastic constructions in civil engineering and on transport actual problems: International scientific and technical conference proceedings, 199-206 (2002)

4. V.K. Faibishenko, Metal cross-bar spatial structures of roofs (VNIINTPI. Moscow, 1990)

5. A.V. Perelmuter, V.V. Yurchenko, Structural Mechanics and constructions calculations 6,18-25 (2012) 
6. V.Yu. Alpatov, I.S. Kholopov, A.V. Solovjev, Effective constructions, materials and technologies in architecture and civil engineering: International conference proceedings, 122-127 (2009)

7. E.V. Gorokhov, V.F. Muschanov, I.V. Romenskiy, A.V. Muschanov, Metal Structures,4, 191-206 (2015)

8. N.N. Halobyta, Herald of Brest State Technical University, 1, 94-102 (2008)

9. N.A. Buzalo, S.A. Alekseev, N.G. Tzaritova, Civil Engineering-2014: Actual problems of industrial and civil engineering: International scientific and pratical conference proceedings, 215-216 (2014)

10. A.V. Muschanov, V.F. Muschanov, I.V. Romenskiy, Unique buildings and constructions, 2, 18-29 (2016)

11. R.I. Khisaimov, L.A. Isaeva, Calculating technical-and-economic index of space frames (Kazan institution of civil engineering, Kazan, 1979)

12. K.I. Mazhid, Constructions optimal design (High school, Moscow, 1979)

13. V.Yu. Alpatov, Metal constructions optimal design (Candidate of Engineering Sciences dissertation, Samara, 2002)

14. V.Yu. Alpatov, A.O. Lukin, S.M. Petrov, Industrial and civil engineering 3, 47-51 (2014)

15. T.Ye. Gordeeva, N.S. Belomytzeva, Architecture and civil engineering: traditions, and innovations, Natural sciences and technospheric safety. Collected works of 72 th allRussia scientific technical conference, 406-410 (2015)

16. A.V. Tur, V.I. Tur, I.S. Kholopov, Joint connections of spatial structures thin-walled bars (Patent 2467133 RF,2011)

17. S.A. Selin, A.V. Tur, V.I. Tur, Joint connections of spatial structures thin-walled bars (Patent 2468157 RF,2012)

18. I.S. Kholopov, A.V. Tur, V.I. Tur, Higher Education Institutions Proceedings. Civil Engineering 4, 104-111 (2012)

19. M.I. Balzannikov, V.Yu. Alpatov, I.S. Kholopov, A.A. Saharov, A.O. Lukin, MATEC Web Conf. 73, 1-6 (2016)

20. I.S. Kholopov, M.I. Balzannikov, V.Yu. Alpatov, A.V. Soloviev, Procedia Engineering 153, 277-282 (2016) 